\title{
ENTRE O REALISMO E O TESTEMUNHO: CRÔNICAS DA VIDA OPERÁRIA, DE RONIWALTER JATOBÁ ${ }^{1}$
}

\section{BETWEEN REALISM AND TESTIMONY: CRÔNICAS DA VIDA OPERÁRIA, BY RONIWALTER JATOBÁ}

\author{
Éderson de Oliveira CABRAL ${ }^{2}$ \\ Ernani MÜGGE ${ }^{3}$
}

\begin{abstract}
Resumo: Este artigo apresenta questões relacionadas aos conceitos de testemunho, desenvolvidas por Giorgio Agamben, e de realismo, trabalhadas por Federico Bertoni. Esses conceitos são aplicados à obra Crônicas da vida operária, de Roniwalter Jatobá, sobre a qual críticos e o próprio autor tecem considerações a partir da ótica do testemunho. Toma-se, como objeto de reflexão, tais comentários e se problematiza os efeitos do real, evidenciando que a literatura de via testemunhal é uma conexão de universos, isto é, uma intersecção entre o real e o ficcional, a qual pode ser uma chave de acesso ao pensamento crítico em relação ao universo do trabalho.
\end{abstract}

Palavras-chave: Realismo. Testemunho. Experiência. Trabalho. Roniwalter Jatobá.

\begin{abstract}
This paper discusses the concepts of testimony, developed by Giorgio Agamben, and realism, by Federico Bertoni. These concepts are applied to Crônicas da vida operária, by Roniwalter Jatobá, on which literary critics and the author himself make considerations from his testimonial tone. Such considerations are taken as the object of analysis, and questions about the effects of reality are raised, revealing that the testimonial literature is a connection of universes. Thus, there is an intersection between the real and the fictional, which can be key to critical thinking about the universe of work.
\end{abstract}

Keywords: Realism. Testimony. Experience. Work. Roniwalter Jatobá.

\section{Breves considerações iniciais}

A ficção em seus produtos sempre plasmou a "realidade", pois imprime e exprime aspectos do real. Dessa forma, o realismo com suas mais diversas faces está a serviço da ficção. O testemunho, como discurso posterior de um acontecimento, tende a estar impregnado de realidade, mas a subjetividade, a memória e tantos outros elementos invadem sua trajetória discursiva e não permitem que qualquer abordagem seja transparente, nítida e isenta. Logo, realismo e testemunho são implicados neste estudo, para que se possa traçar os seus limites e suas intersecções.

\footnotetext{
${ }^{1}$ O presente trabalho foi realizado com apoio da Coordenação de Aperfeiçoamento de Pessoal de Nível Superior (CAPES).

${ }^{2}$ Doutorando no Programa de Pós-graduação em Processos e Manifestações Culturais na Universidade FEEVALE, com período sanduíche na Universidade de Bolonha - UNIBO. Mestre em Linguística Aplicada pela Universidade do Vale do Rio dos Sinos - UNISINOS; edercabral@feevale.br

${ }^{3}$ Doutor em Literatura Brasileira, Portuguesa e Luso-africana pela Universidade Federal do Rio Grande do Sul (UFRGS). Professor da Universidade FEEVALE; ernani@feevale.br
} 


\section{O realismo: um conceito multifacetado}

Federico Bertoni ${ }^{4}$ (2007) aponta que é difícil encontrar um conceito que seja tão conhecido, elusivo, furtivo, difundido e mal compreendido como o realismo, ou seja, é um daqueles objetos teóricos típicos que se reconhece automaticamente, porém dos quais nunca se sabe como fornecer uma definição unívoca. Para Bertoni (2007, p. VII) ${ }^{5}$, "o território do realismo parece ser tão multifacetado, tão cheio de obstáculos e armadilhas que qualquer tentativa de 'fazer um balanço' parece ser um fracasso preventivo".

Bertoni (2007, p. VII, grifo do autor), em Realismo e letteratura, apresenta o conceito de realismo de forma genérica, atitude que encontra justificativa na própria concepção a respeito do tema: o realismo "talvez seja apenas um reflexo inquieto na literatura e na sua paradoxal relação de tensão com aquelas vagas entidades que chamamos de mundo, realidade e experiência".

Portanto, para almejar a compreensão do conceito de realismo, Bertoni (2007) propõe refletir sobre algumas indagações iniciais, relacionadas ao próprio ato criador: como traduzir a experiência por escrito, como representar a "realidade" em palavras e, ainda, como propor uma imagem verbal do mundo que tenha a faculdade de moldá-lo.

A partir dessa reflexão e considerando a literatura um meio artificial que produz algo, impõe-se outro questionamento: o que a literatura pode produzir e o que o realismo pode (re)produzir? A resposta para a indagação pode ser encontrada na relação que se estabelece entre aquele e este: se tanto a literatura quanto o realismo constituem um discurso, ambos estão associados a um poder de criação ou, pode-se, talvez, dizer que existe um poder político, um artifício oportuno e perturbador para incorporar o poder ambíguo da arte de duplicar rostos e figuras, de copiar objetos reais e torná-los mais reais do que os verdadeiros (Bertoni, 2007). Tornando-os mais reais que os verdadeiros, esse poder resultaria em uma vontade política.

Dessa forma, para Bertoni (2007), há uma aproximação aos problemas estéticos e teóricos que está na base da relação entre a literatura e a "realidade". O trabalho de Bertoni (2007, p. IX) repousa na esperança que o seu "esforço possa servir, ao menos, para rediscutir o papel da

\footnotetext{
${ }^{4}$ Docente de Teoria da Literatura na Universidade de Bolonha, onde pesquisa ficção europeia entre os séculos XIX e XX em uma orientação teórica e comparativa. Seus principais campos de pesquisa são a teoria e a história do romance europeu, a tradição do realismo literário ocidental, a teoria da narração, a relação entre literatura e história, a estética da recepção, o Modernismo europeu, as relações entre literatura e cultura visual.

${ }^{5}$ Todas as citações foram traduzidas pelos autores diretamente da língua italiana.
} 
literatura no atual sistema cultural", a qual está

[...] cada vez mais vinculado a uma autodeclarada (mas sempre falsa) verdade, tão invadida pela realidade, quanto incapaz de reconhecer o próprio status da revelação do mundo, que sempre teve, de Homero em diante, as histórias inventadas (BERTONI, 2007, p. IX, grifo nosso).

Seguindo nessa direção, todo o trabalho literário que apresenta profundidade realística não é somente rico em pinceladas sociais, como também em operadores, tais como hábitos, atitudes, comportamentos, rotinas, consumo, etc. E, talvez mais, pois a literatura vinculada ao realismo, como a de Roniwalter Jatobá, está vinculada com uma "realidade" que pode exibir também o modo de poupar, de consumir, de desejar (de transformar em realidade o próprio desejo), de viver (de se relacionar com o(s) outro(s); consigo mesmo; com o próprio trabalho; com o próprio corpo; com aquilo que se abre mão, com o que se cede e com aquilo que não se pode abrir mão) ${ }^{6}$.

As obras realistas podem conter, e é o que nos interessa posteriormente explicitar no produto cultural em análise, uma tempestade de notas sociais. Na medida em que elas traduzem uma eficácia sensorial vívida, que é transmutada na narrativa, plasmada no texto, promovem uma intersecção com o real. Esses aspectos definem um texto como realista. Mas, além disso, aparece, na cena textual, toda a potencialidade semântica que está historicamente condensada na mimese (BERTONI, 2007).

O realismo, portanto, para Bertoni (2007), pode, por um lado, ser entendido como fidelidade; veracidade; crueldade e clareza implacável de uma representação, na qual prevalecem os aspectos desagradáveis e brutais. Por outro, pode ser compreendido como uma atitude baseada em um sentido concreto e pragmático da vida. Então, cabe a seguinte pergunta: o que é o realismo?

O realismo não é apenas uma escola literária, com suas características específicas e que contrariava ou tentava se afastar ou se posicionar diferentemente da escola literária anterior. Nesse viés, Bertoni aponta que

[...] o realismo é uma corrente, uma tendência, uma doutrina que eventualmente encontra seu centro em um específico movimento literário, ou mesmo em uma "escola"? Ou é um ponto de vista, uma aproximação, uma perspectiva sobre o mundo, de qual vêm aspectos determinados evidenciados (como a vida cotidiana, a realidade contemporânea, a dimensão político-social, etc)? (BERTONI, 2007, p. 27, grifo do autor).

${ }^{6} \mathrm{Na}$ obra de Roniwalter Jatobá aparecerão todas essas dramáticas ${ }^{6}$, ou tensões, do universo do trabalho. 
Sobretudo, o autor esclarece, ainda, que o realismo é um método, uma forma expressiva baseada sobre a fidelidade, sobre a objetividade, sobre a verossimilhança ou mesmo sobre a sinceridade da representação. Contudo, talvez, também pode ser visto unicamente como uma convenção que se finge de natural, sendo assim um sistema de regras governado por uma retórica territorial feita de códigos e técnicas, truques e expedientes estilísticos. Apesar disso, Bertoni (2007, p. 27) faz reverberar esta possibilidade: “é uma propriedade intrínseca dos textos, um objetivo do projeto autoral, um efeito de leitura particular ou uma etiqueta (infeliz) aplicada pela crítica e pela historiografia literária”.

Os passos de Bertoni (2007) repercutem o posicionamento de Roman Jakobson (1968), que almejou uma possível definição sobre o realismo, na qual se encontra uma dupla abordagem, que auxilia, pelo menos, no tratamento que se pode dar ao produto cultural a ser analisado. Uma delas é de que se trata de uma intenção, de uma tendência, ou seja, define-se realista a obra que o autor em questão propõe como verossímil. A outra é a seguinte: define-se realista a obra que o examinador julga verossímil.

Se, tanto o autor quanto o examinador dos textos podem defini-los em relação ao conceito de realismo, pode-se verificar, também, que os temas filosóficos, culturais e sociológicos são a base do triunfo do realismo, os quais fornecem

[...] possíveis explicações em termos históricos (a ascensão da burguesia, a economia de mercado, as transformações político-sociais, o advento, a vinda de uma epistemologia racionalista e materialista, a secularização, o cientificismo, o desenvolvimento de uma moderna civilização urbana, etc) (BERTONI, 2007, p. 32).

Os temas, nessa ordem, podem se constituir em um ponto de encontro tanto do autor quanto do leitor, em relação a uma suposta realidade delimitada pelo tempo histórico. Não obstante, e é o que aqui se propõe, o realismo visa, ou melhor, tendencialmente tem como tarefa elucidar diversos aspectos da "realidade", mesmo rechaçando as convenções e construindo, assim, uma ligação com a história, com a historicidade, ou dando "atenção aos dados políticosociais, o uso do detalhe, a objetividade, a hipertrofia do sistema descritivo" (BERTONI, 2007, p. 32). Segundo Bertoni (2007, p. 34), a "arte é um mundo de ilusão e de formas simbólicas", tendo a mimeses como percursora do realismo ${ }^{7}$, e, geralmente, criada pela classe dominante, a

\footnotetext{
${ }^{7}$ No conceito de mimeses, de acordo com Bertoni (2007, p. 39), habitam muitas outras palavras, como "reflexão, cópia, imagem/retrato, reprodução, falsificação, representação, ficção e, evidentemente, o mais próximo de nós: realismo". A mimeses também é teoricamente estruturada por Paul Ricœur em Tempo e narrativa, tomo I, na seção A tríplice mimese (RICEUR, Paul. Tempo e narrativa, tomo I. Campinas: Papirus, 1994, p. 85-125). Bertoni (2007, p. 34) também traz a reflexão de Walter Benjamin, em Angelusnovus (BENJAMIN, Walter. Sobre o conceito da História. In: O anjo da história. Lisboa: Assírio \& Alvim, 2010), na qual o autor, aproxima a literatura da
} 
qual reproduz sua idiossincrasia, realizada como uma "emanação de poder", de "interesse de classe". Ainda, em relação a mimese, Bertoni (2007, p. 52) aponta que

\begin{abstract}
um ponto crucial para delimitar o território da mimese não é tanto a distinção entre real e possível, que é no máximo uma mutação inteligente do reino da lógica: a nuance decisiva, a cláusula na qual toda a diferença elusiva da poesia está nessa "segunda verossimilhança ou necessidade", com a qual a arbitrariedade de todo o possível está de alguma forma contida, trazida de volta à economia e à jurisdição específica da obra de arte.
\end{abstract}

Isso porque a literatura vive constantemente "no vazio, no espaço da exceção e do exagero, ou pelo menos em uma dialética contínua entre familiaridade e assombro, entre o cotidiano e o maravilhoso" (BERTONI, 2003, p. 53).

Para elucidar esse ponto, Antoine Compagnon (1994, p. 109) observa o seguinte aspecto sobre a mimese: esse conceito "não se propõe a explicar as relações entre literatura e 'realidade', senão a produção da provável ficção poética". A mediação estética não consegue a transparência pura, a qual seria uma utopia. Assim, a mediação estética que almeja uma realidade translúcida acaba por ser uma categoria instável, pois, conforme Bertoni (2007), nenhum texto, por mais neutro e objetivo que seja, consegue fugir de uma opacificação, o que não impede que a obra literária, a qual não é um espelho da realidade, seja um "alter mundus" ou “um mundo possível” (BERTONI, 2007, p. 101-102), mas não o próprio mundo em si, senão um mundo ficcional, textual, discursivo.

Para prosseguir, é possível afirmar que uma narrativa realista representa, copia, imita, descreve o mundo real; no entanto, além disso, poderia se dizer, também, que não enfrenta diretamente a "realidade", pois, no ato textual que o constitui, ou seja, em um mundo único, irrepetível, inundado por uma específica tonalidade de luz que é trazido à existência de um ato duplamente criativo, a relação entre o autor e seu leitor se estabelece (BERTONI, 2007).

Dessa forma, como propõe Lorenzo Bonoli (2004, p. 20, grifo do autor) pode-se levar em consideração que "o texto de ficção não reproduz o real, senão que constrói mundos textuais que não preexistem e que não pressupõe uma realidade direta com o mundo de experiência do leitor e do autor" " Isso é um fato, mas não se pode desconsiderar que também "é factual que o estatuto da ficção, na sua definição lógico-filosófica, prescinde dos exercícios de pedantismo dos críticos literários que vão sob o nome de gêneros, estilos ou modos de representação"

história, identificando uma faculdade mimética, isto é, uma capacidade peculiarmente humana de perceber e produzir semelhanças cujo âmbito vital é progressivamente restrito e enfraquecido com o desenvolvimento da civilização, uma vez que é evidente que o mundo perceptivo do homem moderno contém apenas as escassas relíquias daquelas correspondências e analogias mágicas que eram familiares aos povos antigos.

${ }^{8}$ L. Bonoli. Ecriture de la realité. In: Poétique, 137, 2004, p. 19-34. 
(BERTONI, 2007, p. 106-107, grifo nosso). A voz do crítico legitima ou dá a cor ao que será considerado ficção "ou ao que será considerado um modo de representação, como um relato, ou um testemunho" (BERTONI, 2007, p. 107). Cabe, aqui, um ponto para se ter em mente: toda literatura foge da categoria do verdadeiro e do falso (TODOROV, 1981).

Ainda, para poder avançar, "é igualmente verdade que os mundos ficcionais, na sua infinita variedade, podem ter maior ou menor áreas de interseção com o mundo real" (BERTONI, 2007, p. 107), e não é por nada que esses pontos de acessibilidade entre o mundo real de referência e um dado mundo possível possibilitam a avaliação sobre uma mútua compatibilidade em relação a um conjunto de fatores, tais como sujeitos/indivíduos e propriedades, leis físicas e lógicas, representação do espaço e do tempo, coerência histórica ou sociológica, etc. (BERTONI, 2007).

Todo material proveniente do universo real sofre uma metamorfose, a qual se concentra no limiar entre os dois mundos, o real e o ficcional. Pode-se pensar que esses elementos do mundo real se transformam em elementos ficcionais e, assim, o leitor tem o direito de se perguntar se é verdadeiro ou falso, embora, em geral, seja prudente suspeitar da sinceridade ideológica dos autores. Além disso, resta, contudo, "perguntar-se sobre a dinâmica semiótica, hermenêutica e psicológica desencadeada pela realidade inventada", pois "o texto não nega, pelo contrário, afirma os direitos da realidade" (BERTONI, 2007, p. 111).

Convém assinalar que, para Bertoni (2007, p. 112), "a escrita, mesmo aquela que diz estar a serviço do realismo, está sempre no resíduo, no espaço da alteridade e da exceção", em outras palavras, "é uma atividade que percebe, sente e testemunha o mundo real, do qual se alimenta", portanto,

\footnotetext{
o realismo $[\ldots]$ se encontra no meio de um vau, vive em um meio termo fluido entre a realidade e seus fantasmas, dividido [...] entre verdade e necessidade, entre o projeto (ético, ou mais frequentemente retórico) de testemunhar fielmente a experiência e a necessidade (poética) de traí-la, subjugá-la a partir de dentro (BERTONI, 2007, p. 112 , grifo do autor).
}

Assim, a narrativa realista apresenta uma espécie de homologia, na qual se pode pensar estrutura econômica, social e política por meio das estruturas simbólicas, uma vez que, nesse “vau”, nessa passagem rasa do rio, há uma mediação estética que tende a mostrar ou revisar um vislumbre do real, isso porque "a doutrina do verossímil, evidentemente, é radicada em um contexto histórico bem definido, bem preciso" (BERTONI, 2007, p. 134), ou seja, em um horizonte social tangível. Como exemplo, é possível pensar em um romance histórico, que retalha no seu espaço de invenção as próprias dobras da história oficial (BERTONI, 2007). 
Sendo assim, nessa saga de um projeto realista,

[...] o escritor tende a deixar no fundo os grandes personagens e os grandes eventos $\mathrm{e}$ expõe e indaga o terreno móvel e irregular - que o formigamento das "circunstâncias aparentemente insignificantes" das quais emerge a "relação entre o ser humano e seu ambiente social", em um horizonte de um preciso desenvolvimento histórico (BERTONI, 2007, p. 161, grifo do autor).

O realismo, do qual se fala aqui, é aquele que pode se manifestar também a despeito das ideias do autor, o qual poderia se instituir como um "espelho", que reflete algo do real, não exatamente fiel, pois "o poder mimético do espelho está impregnado da inevitável imperfeição do reflexo, mas não é por isto que se deixa combater pela fácil bajulação da falsificação" (BERTONI, 2007, p. 206-207). Ademais, pode-se afirmar que a arte é a coisa mais próxima da vida e, portanto, "a antítese do realismo não seria o idealismo, senão o "falsismo" (LEWES, $1993)^{9}$.

O realismo discutido aqui é, portanto, uma representação "quase fiel” das coisas comuns, longe dos seres ideais, do trabalhador ideal, da esposa ideal, da sociedade ideal. E, por isso, é um conceito tão aberto e plural, uma vez que "não é um objeto específico, não é um dado que se pode etiquetar de uma vez por todas com um designativo rígido" (BERTONI, 2007, p. 313). Talvez se possa representá-lo, como propõe Bertoni (2007, p. 313), “com metáforas tão sugestivas e imperfeitas - como um vau, um meio termo, um espaço de transição (e transcodificação) entre universos não homogêneos - mundo e linguagem, empiria e símbolo, experiência e escrita".

Encerrando a sessão, pode-se dizer que, aventurar-se no conceito de realismo, segundo Bertoni (2007), é usar as vestes de Perseu, herói da visão indireta, o qual não pode olhar o rosto de Medusa, mas que consegue captar a imagem refletida no escudo. Não obstante, para Marcio Seligmann-Silva, (2010b), "a literatura e as artes funcionam como um escudo de Perseu, no qual miramos a face da violência e de suas consequências". É com essa imagem refletida, com esse esforço de visão, com essa estratégia obliqua, com essa mudança de abordagem, que se pode enfrentar o problema do realismo. Faz-se assim, pois é impossível olhar diretamente nos olhos do monstro. Diante da inviabilidade de alcançar um gesto definitivo para o realismo, o qual fica como uma eterna miragem de uma etiqueta, de uma nomenclatura, ele se apresenta como um desafio (BERTONI, 2007).

${ }^{9}$ LEWES, G. H. Il realismo in arte. In: PEROSA, Sergio (org.). Teorie inglesi del romanzo. Milão: Bompiani, 1993. 


\title{
O testemunho
}

Ao abrir a sessão do testemunho, convoca-se Émile Benveniste. Para o teórico, cada vez que a palavra expõe o acontecimento, o mundo recomeça (1976, p. 31). Afirma Benveniste:

\begin{abstract}
"[...] a linguagem reproduz a realidade. Isso deve entender-se da maneira mais literal: a realidade é produzida novamente por intermédio da linguagem. Aquele que fala faz renascer pelo seu discurso o acontecimento e a sua experiência do acontecimento. Aquele que o ouve apreende primeiro o discurso e através desse discurso, o acontecimento reproduzido" (BENVENISTE, 1995, p. 26, grifo nosso).
\end{abstract}

A experiência do acontecimento, que passa pela linguagem, pode estar sob as ledices do realismo, pois com ele se (re)produz uma suposta "realidade", que vem junto com a reconstrução de um evento, nesse caso, por meio do testemunho. Ainda assim, se o realismo tem como projeto ético o de testemunhar a experiência ou se a voz do crítico pode legitimar aquilo que é considerado ficção ou um modo de representação, um relato ou um testemunho, pode-se tentar verificar qual é a relação entre esses conceitos.

Para prosseguir, traz-se, de modo rápido, aqui, Giorgio Agamben (2008), em O que resta de Auschwitz, que explora os escritos etimológicos de Benveniste ${ }^{10}$ (1995b) sobre a palavra testemunho em $O$ vocabulário das instituições indo-europeias. Neste presente estudo, retomase, apenas como ponto de partida, o que Benveniste aborda sobre a questão do acontecimento e do evento por meio da linguagem, mas, além disso, é importante retomar a busca etimológica benvenistiana da palavra testemunho, especialmente, em relação aos termos testis e superstes:

\begin{abstract}
Verificamos a diferença entre superstes e testis. Etimologicamente, testis é aquele que assiste como um "terceiro" (terstis) a um caso em que dois personagens estão envolvidos; e essa concepção remonta ao período indo-europeu comum. Um texto sânscrito enuncia: "todas as vezes em que duas pessoas estão presentes, Mitra está lá como terceira pessoa"; assim o deus Mitra é, por natureza, a "testemunha". Mas superstes descreve a "testemunha" seja como aquele "que subsiste além de", testemunha ao mesmo tempo sobrevivente, seja como "aquele que se mantém no fato”, que está aí presente (1995b, p. 278, grifos do autor).
\end{abstract}

Agamben (2008, p. 27) elabora uma reflexão, vastamente trabalhada, sobre essas duas figuras que representam a testemunha: testis é o termo do qual deriva diretamente a palavra testemunha e significa, etimologicamente, "aquele que se põe como terceiro [...] em um processo ou em um litígio entre dois contendores". Já, por sua vez, superstes aponta "aquele

\footnotetext{
${ }^{10}$ Marcio Seligmann-Silva (2010), em O local do testemunho, também explora a obra benvenistiana.
} 
que viveu algo, atravessou até o final um evento e pode, portanto, dar testemunho disso". Agamben (2008, p. 26) sugere que a testemunha perfeita seria Primo Levi, sobrevivente de Auschwitz, que "quando volta para casa", entre as pessoas, "conta sem parar a todos o que lhe coube viver" e agrega que Levi "não se sente escritor, escreve para testemunhar".

Para dar continuidade, convoca-se, neste ponto, os trabalhos de Seligmann-Silva (2018, 2010, 2005) cuja proposta é pensar o conceito de testemunho como uma nova chave de reflexão para a nova ética da responsabilidade e do cuidado. O testemunho, para Seligmann-Silva (2018, 2010), torna-se importante devido ao acúmulo de uma série de violências que aconteceram no século XX. O autor defende que não se pode dissociar o que acontece no mundo das grandes estruturas políticas e econômicas e que houve muitos massacres promovidos pelos totalitarismos ao longo do século XX. A violência, para ele, é um fenômeno de todo o planeta e gerou a necessidade de se inscrevê-la por meio do testemunho.

A partir da abertura para o testemunho, da recepção, da inscrição, tanto oral como escrita, artística ou imagética, Seligmann-Silva (2018) acredita que se pode tentar construir uma nova ética, ou seja, um novo ponto de vista para se pensar a humanidade e as relações humanas. É nesse ponto que entra a responsabilidade, pois, a partir dessa escuta/escrita, novos pactos de responsabilidade podem ser exercidos, pois parte da humanidade, especialmente a parte mais fraca, ${ }^{11}$ ainda é alvo de violências.

O conceito de testemunho começa a ser pensando teoricamente por Jean Norton Cru (2006), cuja teoria aponta para a ideia de que somente aquele que viveu a guerra no fronte sabe o que é a violência na terra: "aquele que testemunha de modo autêntico a guerra é o militar do fronte: só ele viu e viveu o perigo na carne" (1967, p. 26). Esse posicionamento converge para o conceito de "contravisão", problematizado por Flusser e que convém trazer para esta discussão. Segundo Vilém Flusser [s. d.], “[...] ver é ter olhado para. Ter uma visão é assim o resultado de uma intenção". Portanto, tendo a contravisão como alvo, deve-se ter em mente alguns aspectos: 1) "a possibilidade da contravisão está inscrita no carácter intencional da visão"; 2) "a contravisão não pode ser tida como uma crítica da visão"; 3 ) a contravisão "tem a ver com mãos ${ }^{12}$, que é um problema prático, um problema político"; 4) "não é uma visão do mundo", senão "uma visão da visão" e 5) pode-se "descobrir os vários sentidos que a visão fornece ao mundo e, consequentemente, descobrir outros sentidos possíveis de atribuir ao

\footnotetext{
${ }^{11}$ Por exemplo, os trabalhadores, os grupos LGBTs, os povos indígenas, etc. Os trabalhadores formam uma parte mais fraca por terem sempre acesso restrito às suas necessidades básicas. Mesmo sendo fortes em número, sofrem nas mãos dos dirigentes e autoridades que não zelam e nem garantem um estado mínimo de dignidade.

${ }^{12}$ A relação com as mãos está relacionada à escrita, meio pelo qual é possível inscrever experiências.
} 
mundo" (FLUSSER, s. d.). Assim, a contravisão traz consigo "a possibilidade de inverter a intenção visual” (FLUSSER, s. d.). Portanto, “a intenção da contravisão é observar o nosso serno-mundo e não o mundo em si mesmo" (FLUSSER, s. d.).

Walter Benjamim (1987, p. 115), em um texto intitulado O narrador, direciona a experiência ao "frágil e minúsculo corpo humano", do ser humano do cuidado e que precisa ser cuidado, do ser humano modesto e humilde. Além disso, em Sobre o conceito de história (1987), põe em relevo o ponto de vista dos vencidos, que sempre existiram e sempre foram a maioria. Assim, com essa base, Seligmann-Silva (2018) aponta que se pode aprender a ver essas faces, escutá-las por meio de seus testemunhos.

Georges Perec (1995) traz o testemunho do ponto de vista somático, ou seja, a testemunha tem a necessidade de entender, de narrar e de costurar o mundo e, portanto, "compõe uma obra repleta de enigmas, restrições, jogos e ficções que pode ser lida através de uma via testemunhal" (FUX, 2013). Primo Levi ${ }^{13}$, autor de um dos "testemunhos" mais notáveis do século passado, É isto um homem?, aponta que somente aquele que não olhou nos olhos da medusa e, assim, não morreu e nem ficou emudecido, petrificado, pode testemunhar. Levi (2004, p. 45) joga com o ser mitológico da Medusa, afirmando que, seus textos portam verdades que petrificam ou petrificaram milhares de vítimas. Entretanto, faz a seguinte observação: “deve-se esperar antes um desafogo libertador do que uma verdade com o rosto de Medusa". Levantou-se, aqui, de modo breve, alguns pensadores que abordaram o conceito de testemunho.

\section{Literatura e testemunho: um convite ao sentir, ao despertar para o outro (ou testemunho como conexão de universos)}

A arte nos convida a sentir. O cinema, a música, a literatura, as obras plásticas nos tocam e provocam a empatia. Assim, a arte se constitui em um canal empático, que possibilita sentir o que o outro sentiu, ou, no mínimo, permite que nos aproximemos desse sentimento. Ao realizar uma denúncia, ela mobiliza os sujeitos, que a contemplam e sentem uma compaixão transformadora.

Na cultura há ambiguidades, uma vez que, por trás das grandes construções históricas, há um sem número de seres humanos sacrificados - que sempre tendem a ser os esquecidos (os invisíveis, os invisibilizados). Dessa forma, a expressão artística pode ser um -ouse valer de ou

\footnotetext{
${ }^{13}$ Imagem retirada de um poema escrito a Mario R. Stern, que, assim como Levi, testemunhou os eventos da Shoah: Ho due fratelli con molta vita alle spalle / nati all'ombra delle montagne. / Hanno imparato l'indignazione / nella neve di un paese lontano, / ed hanno scritto libri non inutili. / Come me, hanno tollerato la vista / di Medusa, che non li ha impietriti. / Non si sono lasciati impietrire / dalla lenta nevicata dei giorni (STERN, 1991).
} 
receber o valor de- testemunho, ou melhor, é capaz de ser conduzida por uma via testemunhal. A literatura pode ser um testemunho, em outras palavras, o testemunho, o luto, o trauma, a memória ou a pós-memória, seja ela de terror ou de denúncia, transmutada por meio da arte. Aqui podemos citar brevemente o conceito de tremendum horrendum, de Paul Ricœur (1997). O tremendum possui duas faces: o horrendum e o fascinosum. Por um lado, o tremendum horrendum destaca e enfatiza uma causa que merece ser defendida, mesmo estando repleta de horror. O horror, segundo Ricœur (1997, p. 325), relaciona-se a um episódio que "é necessário nunca esquecer". Portanto, o tremendum horrendum constitui a motivação ética da história das vítimas. Por outro lado, o tremendum fascinosum é a reprodução da história dos "vencedores", do fascínio e da admiração, do pensamento reconhecido (RICCEUR, 1997). A literatura serve como local de construção da imaginação e da reconstrução da memória, que pode nos transportar ou nos aproximar. Além disso, serve também como local de jogo da memória, dos traumas, ou de jogo com os sentimentos e com a (re)elaboração e (re)visão do passado.

Um ponto de forte impacto, para Seligmann-Silva (2018, 2010), é a construção da empatia, a elaboração do teatro da compaixão pelas diversas linguagens, que determinam, que direcionam, com quem podemos - ou não - nos identificar. Isso é o que gera, de modo relevante, a construção de identidades, a capacidade e a incapacidade de compaixão, ou seja, há uma construção narrativa, ou midiática, daqueles que podemos amar e daqueles que podemos odiar ou esquecer (invisibilizar), tal como uma pedagogia da indiferença.

A literatura com caráter de testemunho pode atuar como um operador essencial entre a responsabilidade e projetos de ação do poder. Esse testemunho enuncia e traz consigo a força do apelo, da dor, do sofrimento, do desgaste dos corpos ou da sua destruição e do (im)possível esquecimento ou invisibilidade. A seguir, implicamos o capital teórico apresentado acima na obra Crônicas da vida operária, de Roniwalter Jatobá.

\section{Visão de Crônica de vida operária pelos críticos e pelo autor}

Bertoni (2007, p. 96) oferece uma direção, diante de seus paradoxos, para pensar a perfeição do realismo, de uma obra realista: "o paradoxo supremo do realismo [...] é que a sua perfeita realização coincide com a negação da obra de arte". Essa é uma intenção tanto do autor, Roniwalter Jatobá, no prefácio da obra, quanto dos críticos de Crônicas da vida operária, quando apontam que o livro é de operário para operário, mas também quando direcionam ela como "testemunho", que deixa o texto num limiar entre a ficção e a realidade.

Os críticos literários, ao comentarem a obra de Roniwalter Jatobá, Crônicas da vida 
operária, como Fernando Morais ${ }^{14}$ (2006, p. 5), destacam a obra como uma fuga. Nos anos 70, entre os muitos críticos literários, rondava uma névoa espessa, a qual carregava a declaração de que o Brasil já não tinha “uma literatura que prestasse” após Guimarães Rosa (MORAIS, 2006). Mas Crônicas não está entre elas. Morais conheceu a obra quando participava como jurado do Prêmio Casa das Américas recebendo-a como "gênero 'Testemunho"” (MORAIS, 2006).

Morais (2006, p. 7) ressalta que a obra de Jatobá é conhecida para quem se interessa pela vida dos habitantes da periferia. Destaca que ela impressiona, pois "seus personagens, calados e magros, falam de uma gente que chega a São Paulo de pau-de-arara, viaja como pingente nos trens de subúrbio e fabrica máquinas e edifícios de que jamais desfrutará”. Morais (2006, p. 7) acrescenta, ainda, que "a produção cultural brasileira reflete muito pouco sobre a realidade da população, daqueles noventa milhões que não se beneficiariam do "milagre econômico"' e, assim, vê Crônicas como uma obra que cumpre essa função: "um livro sobre e para o operário urbano, o ex-camponês que virou metalúrgico ou peão de obra, o bóia-fria que se perdeu na cidade grande".

Renato Pompeu declara que Jatobá era um dos poucos no Brasil, à época, que escrevia sobre "um tema fora de moda na nossa literatura: a classe operária" (MORAIS, 2006, p. 5). Pompeu elogia a obra e a descreve como "uma flor que nasce da vida operária" e chega a dizer que a narrativa tem "uma linguagem que exige honra e respeito", pois Jatobá "aprendeu com os trabalhadores a honrar o ofício que exerce, no caso, o de escritor”. Além disso, Pompeu afirma que Jatobá retrata as diversas revoltas dos operários, tais como ameaças de demissão, baixos salários, más condições de trabalho, etc. Ainda, Arnaldo Xavier, poeta e migrante, sobre Crônicas, aponta que Jatobá registra “o cotidiano das fábricas do ABC nos anos 70” e que dessa época “o único registro seria sua literatura” (JATOBÁ, 2006, p. 14).

Luiz Ruffato, organizador da coletânea Contos antológicos de Roniwalter Jatobá, no texto de apresentação intitulado Roniwalter Jatobá e a literatura proletária, aponta que "se nos debruçarmos sobre a produção ficcional brasileira ao longo do tempo, poucas vezes vamos flagrar personagens exercendo algum tipo de atividade laborativa" (RUFFATO, 2009, p. 13). Para Ruffato (2009, p. 13), de modo geral, os escritores brasileiros, "bem-nascidos”, satisfazem suas necessidades de criação no próprio âmbito da classe média, "nicho onde o trabalho nem sempre é bem visto". Ruffato percebe isso quando lê os comentários do crítico paulista João Luiz Lafetá sobre a obra de Oswaldo França Junior, pois Lafetá sugere que o trabalho é "coisa

\footnotetext{
${ }^{14}$ Fernando Morais é jornalista, biógrafo e escritor brasileiro. Sua obra literária é constituída por biografias e reportagens. Publicou, entre outros livros, A ilha, Olga (o qual tem uma adaptação para o cinema) e Chatô - O rei do Brasil.
} 
rara numa literatura que quase sempre o desprezou e evitou representá-lo" (LAFETÁ, 2004, p. 251).

Em relação à temática do trabalho, realmente são poucos os escritores que representam esse universo. Ruffato (2009, p. 13), em relação a esses poucos, adiciona que

quando extrapolam os seus horizontes, caem na tentação ou de idealizar o trabalhador, exibindo a exploração de que é vítima para combater politicamente sua opressão, ou de romantizar a figura do malandro ou do bandido, como pretenso contraponto rebelde às injustiças da sociedade.

Ruffato (2009, p. 14) destaca os dados biográficos de Jatobá, apontando que é um dos poucos autores que conhecem as aflições da classe trabalhadora:

Roniwalter Jatobá, mineiro de Campanário, radicado em São Paulo desde 1970, é uma dessas exceções. Migrante, foi motorista de caminhão, operário metalúrgico e gráfico, antes de se formar em jornalismo [...]. Mas, vivência apenas não faz boa literatura. $\mathrm{O}$ que torna Jatobá um grande escritor é sua capacidade de transformar a matéria bruta da vida em Arte.

Assim, como um elogio, coloca a obra de Jatobá como um marco da literatura proletária. Após a obra de Jatobá, há uma descontinuidade na literatura brasileira com a temática do trabalho, o que não é uma surpresa, uma vez que a história dos oprimidos no Brasil é fragmentada. De uma forma ou de outra, todavia, o tema surge novamente de forma impactante nos textos de Ruffato, como se pode constatar na pentalogia Inferno Provisório (2016), a qual é composta pelos romances Mamma, son tanto felice; O mundo inimigo; Vista parcial da noite; O livro das impossibilidades e Domingo sem deus. Esses textos têm uma linha temática que representa uma trajetória do operário brasileiro a partir da metade do século $\mathrm{XX}$ até a contemporaneidade.

Ainda no texto de apresentação, Ruffato (2009, p. 14) agrega alguns pontos importantes sobre os contos de Jatobá, em que ressalta o impacto dessa literatura, a qual considera de muito valor:

talvez, a literatura de boa qualidade exija uma dose mínima de veracidade - e são escassos os autores brasileiros conhecidos das mazelas da classe trabalhadora. Roniwalter Jatobá é uma dessas exceções. Ele praticamente instaura a literatura proletária brasileira [...] (grifo nosso).

Ruffato (2009) aponta aparições do trabalhador urbano em alguns romances, tais como $O$ cortiço, de Aluísio de Azevedo, de 1890; Os corumbas, de Armando Fontes, de 1933 e $O$ moleque Ricardo, de José Lins do Rego, de 1935. Além dos romances, aponta alguns outros 
contos, tais como os reunidos no livro Contos Novos, de Mário de Andrade, de $1947^{15}$ e no Brás, Bexiga e Barra Funda, de Alcântara Machado, de 1927.

Ruffato (2009, p. 14), ao afirmar que Jatobá "praticamente instaura a literatura proletária brasileira”, deixa enquadrada no tempo a literatura proletária entre 1930 e 1937. É uma literatura designada também como proletária, pois se afastava da temática modernista e se aproximava do cotidiano dos pobres, dos trabalhadores, dos oprimidos. Trabalhava a temática da miséria na degradante situação das urbes e dos parques industriais. $\mathrm{O}$ tom das obras era de relato, aproximando-se do realismo socialista, isto é, apresentava uma tentativa de descrição "fiel" dos fatos.

Nesse período, de 1930 a 1937, e um pouco adiante, surge o romance Gororoba, de Juvêncio Campos, de 1932; Parque industrial, de Patrícia Galvão, de 1933; A escada vermelha, de 1934, A revolução melancólica, de 1943 e Chão, de 1945, de Oswald de Andrade, que avança um pouco mais no tempo em relação a essas produções. Além desses títulos, ainda encontramos Navios iluminados, de Ranulfo Prata, de 1937, e Cacau, de 1933, Suor, de 1934, Jubiabá, de 1936, Capitães de areia, de 1937 e O Cavaleiro da Esperança, de 1943, estes últimos de autoria de Jorge Amado. Essa literatura proletária fica estancada no tempo histórico e não somente retoma fôlego nos anos 70, como também é instaurada por e com Jatobá em seus contos, por meio de uma outra configuração, um outro realismo de contravisão, isto é, pela via testemunhal. Segundo Ruffato (2009, p. 14), "Jatobá é pioneiro ao alicerçar no operário a sua obra" e, por meio delas, “apenas no final dos anos 70 o proletário ganhará espaço na literatura, não mais como símbolo idealizado, mas como personagem complexo e veraz”. Além disso, Ruffato (2009, p. 16) emplaca o seguinte fato: "O primeiro autor que vai tratar do tema é Roniwalter Jatobá. E até hoje praticamente ninguém seguiu o caminho pioneiro por ele aberto" ${ }^{16}$.

No posfácio da $6^{\mathrm{a}}$ edição de Crônicas, Flávio Aguiar ${ }^{17}$ (2006, p. 75) aponta que esse livro captou diversos momentos, tais como "o mundo da ditatura, aquele que nunca ia terminar", que “era irreversível” e que declarava que "o Brasil era o país do futuro; agora o futuro chegou". Aguiar (2006, p. 76) defende que o texto de Jatobá mostra que esse futuro era uma "mistura de horror com uma infinita capacidade de resistência sempre em teste", além da "degradação do

\footnotetext{
${ }^{15}$ A obra reúne narrativas curtas escritas durante a vida do autor, mas foram publicadas após sua morte, em 1947. Os contos foram escritos entre 1924 e 1945, entre eles está o célebre Primeiro de maio.

${ }^{16}$ Caso se estabeleça como ponto de diálogo a literatura italiana, tem-se uma representação do trabalhador e do trabalho muito mais antiga e constante. Dois textos que mostram, ao longo da história da literatura italiana e de sua constância, um panorama breve dessa relação são Lavoratori e lavoro nella letteratura italiana, de F. Carnevale (2013) e Letteratura e lavoro in Italia, de Angelo Ferracuti (2013).

${ }^{17}$ Professor de Literatura Brasileira da Universidade de São Paulo, autor de Anita, livro que foi prêmio Jabuti na categoria romance em 2000.
} 
cotidiano", e visa a olhar os "escombros, as vidas em estado de pobreza, com dignidade ou em ruínas, que davam o ritmo secreto daquele Brasil, o não-contado, o descontado". Para Aguiar (2006, p. 76), o texto de Jatobá retrata os aspectos singular e plural da vida operária e aponta que é um "testemunho" da "multiplicação de olhares". Aguiar (2006, p. 77) afirma que a literatura de Jatobá, e as que se assemelhavam, enfrentaram um "paredão de preconceitos", pois foram taxadas de "populista, naturalismo requentado, prosa referencial superada, diluidora, etc.", e afirma que a crítica não percebeu que nessa literatura figuravam "vozes antes quase inaudíveis no terreno literário, a não ser pelo viés repetido do pitoresco ou da falta de educação formal, as vozes do mundo do trabalho".

A literatura de Jatobá é, para Aguiar, “confessional e testemonial”, “dá testemunho: atesta, em primeiro plano, que aquelas vozes existem e merecem ser escutadas". Por fim, fechando seu posfácio, Aguiar (2006, p. 77-78, grifo nosso) aponta que "essa literatura afirma portanto a palavra do escritor como herdeira de um patrimônio coletivo, ainda que original em sua individualidade" e que Crônicas "é um dos principais legados de Roniwalter e os de sua geração: o testemunho de que aqueles tempos dilacerantes não dilaceraram de todo os espíritos”.

Celso Frederico ${ }^{18}$ comenta a obra de Jatobá na coletânea No chão de fábrica, com o texto intitulado Dignidade operária, mundo desumanizado. Frederico (2016) aponta que, na primeira edição de Crônicas, Jatobá "firmou-se como um escritor vigoroso que trouxe à cena literária o mundo do trabalho". Em relação à literatura brasileira, Frederico (2016, p. 193) se posiciona de modo similar a Ruffato, não apenas afirmando que "Roniwalter é honrosa exceção", pois escreve sobre a vida dos operários, como também realça a experiência, os dados biográficos do autor, evidenciando a relação, a identificação do escritor com o mundo do trabalho: "há razões biográficas para essa identificação, visto que o autor não fala de fora sobre o mundo do trabalho e de seus personagens: ele mesmo, migrante, saiu do norte da Bahia trabalhando como motorista de caminhão, office-boy e operário na indústria metalúrgica em São Bernardo do Campo". O Crônicas de Jatobá, para Frederico (2016), é uma espécie de literatura de formação que registra uma trajetória migrante, a condição operária, a precariedade vivida e a superexploração do trabalho. Esses mesmos aspectos negativos do trabalho, representados na obra, são percebidos no mundo empírico, sendo o gatilho para reivindicações dos trabalhadores e o surgimento do movimento operário de São Bernardo, do qual emerge Luiz Inácio Lula da Silva, líder do movimento, que posteriormente será presidente do Brasil. Frederico (2016, p. 194, grifo nosso) ainda aponta que o Crônica registra um momento histórico: "o melhor documento que se

\footnotetext{
${ }^{18}$ Professor na Escola de Comunicações e Artes da Universidade de São Paulo.
} 
produziu naquele período. Trata-se, portanto, de uma obra que possui um inestimável valor documental. Mas, tão grande como o valor documental é o seu valor artístico”. Mais uma vez, com posicionamento similar de Ruffato, Frederico (2016, p. 196, grifo do autor) aponta que

\begin{abstract}
A boa literatura rejeita estereótipos e também não aceita passivamente, como algo "natural", as condições deprimentes em que os homens foram lançados. Contra a desumanização, o escritor toma partido, colocando-se ao lado dos seres humanos. Roniwalter Jatobá, assim, se insere na boa tradição do romance realista.
\end{abstract}

Anteriormente, emergem obras que são cunhadas de realistas socialistas, por terem como intento expor a estrutura social e a opressão. No entanto, Frederico (2016, p. 195) tem o seguinte posicionamento sobre as obras do realismo socialista: "nada realistas, com personagens maniqueístas e desprovidos de contradições internas, ou, ainda, romance-reportagens que só se atêm as exterioridades". Jatobá, por sua vez, é classificado pelo autor como pertencente à linhagem realista, que trouxe com sua vivência a revelação de um mundo pouco frequentado pelos nossos escritores" (FREDERICO, 2016, p. 196).

Traz-se, para este trabalho, essa relação de críticos e conhecedores da obra de Jatobá, não para justificar ou mostrar que o escritor produz uma obra realista, mas para destacar a conexão dos textos de Jatobá ao testemunho, documento ou relato. Alguns desses críticos falam de boa literatura e de literatura de qualidade, outros elogiam e reconhecem a obra de Jatobá como sendo uma ficção. O que se realça, nessa sessão, são as vozes desses críticos que apresentam elementos comuns, como o testemunho e a experiência.

O próprio Roniwalter Jatobá (2006) situa sua obra como um testemunho, uma vez que o texto de apresentação da $6^{\text {a }}$ edição de Crônicas da vida operária ${ }^{19}$, lançado pela editora Lazuli, é intitulado como Testemunhos do nosso tempo (JATOBÁ, 2006, p. 9). Nesse texto, o autor expõe que a construção literária é fruto de sua vivência na indústria automobilística no $\mathrm{ABC}$ paulista, na Karmann-Ghia, no qual foi registrado como ajudante geral. O Crônica da vida operária traz, segundo o escritor, "histórias sobre operários do $\mathrm{ABC}$ " e "relatos dos operários do ABC" (JATOBÁ, 2006, p. 11). O Crônica é a soma dessas "histórias" e "relatos", que mais tarde participaria do concurso literário cubano Casa das Américas, pois se encaixaria no gênero "testemunho".

Abre-se, aqui, um pequeno interlúdio: o testemonio recebe status de gênero por meio do concurso literário Casa de las Américas, nos primórdios dos anos 60, como detalha SeligmannSilva (2005, p. 87): “na Hispano-América passa da função testemunhal da literatura para uma

\footnotetext{
${ }^{19}$ Crônicas da vida operária é o título dado por Luiz Egyto, editor do jornal Versus, à coluna que Jatobá escreveu nesse periódico, que posteriormente se tornou um livro.
} 
conceitualização de um novo gênero literário, a saber, a literatura de testemonio". Esse gênero, na América Latina, "tem um peso mais de política 'partidária' do que 'cultural': aqui ocorre uma convergência entre política e literatura" (SELIGMANN-SILVA, 2005, p. 87). Além disso, Seligmann-Silva destaca o papel de Cuba, que, para ele, "terá um papel-chave na institucionalização desse gênero", pois "[...] esse país assumiu a liderança de um movimento de revisão da história que passou a ser recontada a partir do ponto de vista dos excluídos do poder e explorados economicamente". Da mesma forma, Gilmar Penteado (2017, p. 242, grifo nosso), ao comentar a obra de Carolina Maria de Jesus, Quarto de despejo, também afirma que "o testemonio ganhou status de gênero literário, principalmente pela interferência de Cuba, mais precisamente pelo concurso literário "Casa de las Américas". O nome da autora apareceria na revista, criada por esse centro cultural, no seu número três, no ano de 1966, já sendo assimilado pelo conceito de testemonio. João Camillo Penna, em seu Escritos de sobrevivência, traz a voz de John Beverley, que também fala dessa importante ação do centro cultural cubano: “A decisão da Casa de las Américas (o Ministério da Cultura de Cuba) de criar um prêmio especial para a categoria de testemonio em 1970 explicita o vínculo entre a revolução cubana e a criação deste espaço enunciativo na América Latina".

Segundo o próprio Jatobá (2006, p. 12), o Crônica tem uma "linguagem simples, sem rebuscamento, seca, sem adjetivos, e que refletia o modo de falar do migrante nordestino, com suas características de homem rural em contato com a sofrida condição de homem urbano". Jatobá (2006, p. 13) não se coloca "numa redoma de cristal, como fazem muitos escritores neste país, escrevendo para meia dúzia de amigos e assumindo uma postura intelectual, de donos da verdade"; assim, escreve para ser lido e entendido. Conforme o próprio autor, que fez leituras na periferia paulista, suas histórias eram bem recebidas, "muitas pessoas gostavam", pois se identificavam com elas, assim como "outras pessoas que não gostavam pelo mesmo motivo", uma vez que "as histórias faziam lembrar determinadas épocas que preferiam esquecer" (JATOBÁ, 2006, p. 14). Talvez o rechaço tenha acontecido porque Jatobá afirma que sua literatura

revela por dentro o inferno da indústria automobilística do $\mathrm{ABC}$, descrito por quem o conheceu como trabalhador; o inferno dos turnos de trabalho; o inferno da mais-valia que se transforma em lucros multinacionais e em danosos investimentos de estrangeiros na Amazônia; o inferno do facão (a ameaça permanente da demissão, como instrumento de chantagem contra os que se recusam a fazer horas extras ou a trabalhar nos domingos) (JATOBÁ, 2006, p. 14, grifo nosso).

A recepção positiva da leitura, por sua vez, pode se dar pelo compartilhamento da situação 
trágica, pois há um sentido próprio para quem pertence à comunidade e se identifica com o cotidiano narrado. Em continuidade, Jatobá (2006, p. 16, grifo nosso) declara que seus contos "refletem o trabalhador no difícil dia-a-dia de São Paulo" e procuram "dar voz ao trabalhador [...], principalmente o migrante nordestino que vive na metrópole”. Ainda, ao falar de questões de pertencimento às correntes literárias, afirma que pertence à "ala dos ficcionistas brasileiros ligados à realidade e com fito de comprovar uma temática nossa, brasileira, longe de esgotarse. Escrevo com o que sou [...]". Jatobá escreve para trazer à tona, na tentativa de não se deixar obliterar, não somente a década de 50, na qual aconteceu a maior onda migratória das regiões Norte e Nordeste, em direção ao "paraíso" industrial paulistano, recém estruturado, que recebia esse fluxo migratório em suas indústrias instaladas nas periferias, mas também as décadas posteriores, até os anos 80 . Seus contos procuram relatar a saga da (sobre)vivência desses trabalhadores ao redor da sua esfera laboral.

Uma mescla de trabalho duro e sonhos estão impregnados nos contos de Jatobá; “e é nessa leva migratória que tento fazer minha literatura" (JATOBÁ, 2006, p. 16). Segundo o autor, seu caminho ficcional é difícil, pois escreve "sobre a parcela pobre do povo e não, como de costume de grande parte dos escritores brasileiros, o mundo limitado e mesquinho da classe média" (JATOBÁ, 2006, p. 16-17). Sua obra é exceção, assim como expõem Ruffato (2009) e Frederico (2016), ou seja, trata-se de uma literatura de êxodo.

\section{Do realismo e do testemunho na obra de Jatobá: uma visão macro}

O testemunho entra na perspectiva do não se deixar esquecer, do arquivar. A palavra trabalho, por sua vez, é ambígua, multifacetada, pois carrega nuances tanto positivas quanto negativas. Essa ambiguidade se dá pela relação entre trabalhadores e governo ou trabalhadores e empresas, que estão sempre em um sistema de interindependência, no qual apenas uma das partes está destinada ao esquecimento. Lembra-se do operário, do trabalhador, quando ele é necessário como corpo que produz, mas, ao mesmo tempo, esquece-se dele, dos seus direitos, do seu desgaste e de sua manutenção.

A literatura é um meio de resistência, um modo de não abrir mão da esperança, de não ceder ao desejo de melhora, pois, quando se renuncia ao desejo, justamente se intensifica e se acelera a crise. Todas as ameaças que rondam o universo do trabalho podem, efetivamente, concretizar-se. Talvez não se consiga impedir nada por meio de ações individuais ou coletivas, 
mas, no mínimo, pode-se retardar que as crises aconteçam por meio de manifestações. A literatura, como manifestação, pode mostrar que todas as ameaças são evitáveis. Há momentos que a sociedade está na beira do abismo político e econômico, mas é capaz de se reinventar de algum modo - ou inventar por algum meio, e é exatamente aí que pode entrar a literatura. E, ainda assim, se não se puder evitar os cortes dos direitos, que haja produtos culturais que consigam retardá-los ao máximo, por meio do testemunho ou da memória. A literatura é um espaço para semear tal esperança e serve como um meio para as vozes politicamente minoritárias encontrarem um espaço de manifestação, um campo político de batalha ou uma chave de acesso a uma face crua da sociedade ou para o pensamento crítico.

Para Seligmann-Silva (2008), se a sociedade aprender a olhar essas faces plasmadas na literatura e a escutar os testemunhos, como uma pedagogia da escuta, da leitura, pode-se construir um outro modelo de ética, um outro pacto social de convivência e, assim, reaprender a construir o comum.

A partir desse posicionamento, pode-se olhar a literatura de Roniwalter Jatobá, especialmente a obra Crônicas da vida operária, na qual os personagens trabalhadores também apresentam uma face em que são vítimas da violência, não só pelo (ab)uso dos seus corpos no âmbito do trabalho, mas por serem empurrados constantemente para a periferia, para as margens, não somente da urbe, como também dos direitos.

O produto literário de Jatobá serve como um testemunho, pois sua literatura constrói imagens (estéticas) de um cenário laboral. Estas são poderosas, pois se apresentam como um testemunho de um contexto econômico, político e social. No Crônicas, está inscrito esse cenário: há, na narrativa, o desenvolvimento de personagens, e, concomitantemente, a inscrição do testemunho do contexto nacional da época, por meio de denúncia e do retrato do cotidiano duro do trabalhador. $\mathrm{O}$ ato de narrar o cotidiano não apenas registra a dinâmica dos trabalhadores, mas também explicita o desgaste, o uso desses corpos que trabalham, que constroem e dão ritmo à economia, mas, ao mesmo tempo, se esfarelam na memória, resistindo a forças que os jogam para fora da rememoração e da empatia.

A literatura de Jatobá pode ser vista como memento, não só como testemunho, pois é uma homenagem aos trabalhadores que são massacrados pelas técnicas, pelos modos de produção, já que suas vidas e corpos se misturam com os objetos, construções e artefatos que eles próprios forjam. Essa literatura, que tem o trabalho e o trabalhador como mote, evidencia que, muitas vezes, os operários não são apenas vítimas dos modos de produção do século XX, mas que também são tratados como restos, como aquilo que não merece compaixão. Esse produto literário que versa sobre o trabalho faz esse jogo de aproximação, de empatia, e pode promover 
um trabalho crítico, não sistematizando o trabalhador como vítima, mas como um de nós, subjetivando e intersubjetivando personagens, produzindo a sensação que ele é como qualquer um de nós. Essa literatura pode ter um caráter de testemunho, de denúncia, que implica no ataque não tão explícito de certas camadas da sociedade, as quais rechaçam e querem obliterar esses testemunhos e denúncias. Em Crônicas, o cotidiano dos trabalhadores está no primeiro plano. Não é a classe dominante que está em cena, senão uma apresentação do cotidiano dos trabalhadores e sua trajetória em determinado período histórico. A narrativa de Jatobá não apresenta explicitamente a ideologia dominante, mas a presença e suas consequências na vida dos trabalhadores. Assim, sua obra revela não somente observação, como também uma contravisão, um testemunho.

Na obra de Jatobá, o testemunho pode ser uma "resposta ética e política apropriada a possibilidade mais de solidariedade do que de caridade" (Beverley; Zimmerman, 1990, p. 177). Ademais, "o testemunho" de Jatobá pode apresentar uma dinâmica de solidariedade em relação às lutas particulares. Jatobá, em Crônicas, apresenta essa suposta solidariedade em busca de uma subjetivação dos personagens, para que suas identidades singulares sejam preservadas na história da incorporação dos nomes individuais, dos rostos, dos corpos, dos modos dos trabalhadores, o que promove um poder que os torna mais reais do que os verdadeiros, devido à profundidade realística de suas vidas, as quais são transmutadas na narrativa.

\section{Considerações finais}

As notas sociais que são dispostas nas narrativas plasmam, configuram um vau que nos permite transitar criticamente no universo do trabalho, pois o texto de Jatobá promove uma intersecção com o real, apresentando personagens típicos em circunstâncias típicas. Pode-se, ainda, problematizar esse aspecto típico, emblemático, simbólico em análises detalhadas de cada conto ou novela de Jatobá. Também é possível afirmar que as narrativas transcendem o plano da vida cotidiana, pois revelam os problemas essenciais, representando os personagens humanos e socialmente típicos e as grandes forças sociais e as bases econômicas do desenvolvimento histórico.

As narrativas de Jatobá, não apenas por plasmarem sua experiência, sua biografia, mas também por seus narradores-protagonistas fazerem parte da classe representada, proporcionam uma visão convincente e apurada da realidade que os operários do $\mathrm{ABC}$ paulista atravessaram. 
Existe, além disso, uma sinceridade artística que transfigura, que plasma a vida contemporânea e as condições de vida dos trabalhadores nos textos.

Jatobá não apresenta narradores não-confiáveis; pelo contrário, seus narradores e personagens contam histórias plausíveis ou confiáveis, para enfatizar o conteúdo e as representações. Pode-se perceber que há, nas narrativas, um olhar autêntico sobre a experiência humana, no seu devido recorte, a vida dos trabalhadores e suas nuances, para, dessa maneira, oferecer ao leitor uma visão privilegiada dos detalhes sobre a identidade dos agentes e sobre as circunstâncias (o aqui e agora singular) vivenciado e exposto em detalhes.

Quando se refere ao realismo como "o ato de copiar uma cópia", a estratégia narrativa não ofusca o efeito do real na narrativa, muito pelo contrário, o presentifica, e caso se tenha em mente a contravisão de Flusser, a realidade plasmada nas narrativas não mostra apenas uma visão do que o autor viu e prefigurou no texto, mas promove uma visão crítica fundada nessa intersecção com o real. Assim, essa visão plasmada não é apenas mostrada, como também pode promover uma visão diferente da e na própria realidade, aproximando-se do cuidado, da ética e do bem comum.

Caso se defina como realista a obra que o examinador julga verossímil (BERTONI, 2007), a obra de Jatobá faz com que se elucidem os diversos aspectos de uma realidade pouco estudada no âmbito da literatura: o universo do trabalho no Brasil. Geralmente produzida pela classe dominante, a literatura constantemente reproduz uma idiossincrasia, emanando seu poder de dominação, estereotipando o trabalhador e colocando-o regularmente como um subalterno. Se a literatura vive constantemente no vazio, no espaço da exceção e do exagero, como propõe Bertoni (2007), os mundos textuais de Jatobá transfiguram uma realidade e expõem uma exceção: subjetivam e evidenciam a vida daqueles que podem facilmente ser esquecidos ou ser invisibilizados ou até mesmo tratados como não-pessoas.

Se a voz do crítico legitima o que será considerado ficção, muitas vezes se adjetiva a literatura de Jatobá como um relato ou um testemunho. É claro que isso se dá pelas explícitas áreas de interseção com o mundo real, as quais foram transformadas em elementos ficcionais, resultando numa dinâmica semiótica/semiológica curiosa: é literatura, é testemunho? Essa é uma pergunta retórica e peremptória, mas, ao mesmo tempo, é interessante elucidá-la: antes de tudo, é uma pergunta redundante, pois o testemunho é literatura, é ficcional. Essa questão é crucial para investigar a obra de Roniwalter Jatobá, pois testemunho e literatura não são alternativas, ou seja, é literatura de testemunho. Por isso, superar essa dicotomia é importante, pois o testemunho não é algo de menor quando se relaciona com a literatura. Pode-se ter uma má literatura e um bom testemunho ou vice-versa. Existe uma conexão que faz com que essa 
pergunta não seja dispensável, porque, por um lado, há uma literatura que tem o apego mais forte ao real e, por outro, há uma literatura que serve como salvação de um passado traumático, assim como há literatura com um menor apego ao real.

Bertoni (2007) afirma que a escrita, mesmo aquela que diz estar ao serviço do realismo, está sempre no espaço da alteridade e da exceção, portanto, é uma atividade na qual se percebe o tom testemunhal, pois se alimenta da experiência e do próprio mundo real. Por isso, a narrativa de Jatobá fornece uma chave para se pensar a estrutura econômica, social e política por meio das estruturas simbólicas. É nítido que os textos de Jatobá deixam no fundo os grandes personagens e os grandes eventos e se fixam em um terreno irregular, dramatizando e ampliando o poder de circunstâncias aparentemente insignificantes, das quais emerge a relação entre o ser humano e seu ambiente social, nesse caso, seu ambiente laboral e sua trajetória de vida.

A literatura de Jatobá é uma representação das coisas comuns, do homem comum, do ser singular da multidão; por isso designa nomes, subjetivando os homens e mulheres comuns que, na massa extratextual, são tidos como apenas mais um ser, mais um número, mais uma entidade sem força de expressão, seguindo o plano da subalternidade. Talvez se designe tal literatura como testemunho, pois há uma fusão entre mundo e linguagem, empiria e símbolo, experiência e escrita, evidenciando situações e problemas, dentro de uma historicidade que se pode especificar. Talvez se designe tal literatura como testemunho por ela se relacionar com aquilo que está no mundo descrito e prefigurado do autor e escritor.

Caso seja a literatura de Jatobá um testemunho, como o autor e críticos apontam, que testemunho seria? Se Jatobá fosse uma testemunha, qual seria? A superstes, ou seja, aquela pessoa que testemunha e, ao mesmo tempo, é sobrevivente, como aquele que se manteve no fato que esteve presente? Pode-se dizer que sim, pois a superstes é aquele que viveu algo e pode atravessar todo um evento, e, portanto, pode dar testemunho disso. A experiência de Jatobá garante, ou melhor, a apresentação de seus dados biográficos faz emergir esse ponto. É possível levantar tal questão, pois, a partir de suas narrativas, é possível depreender uma ética da responsabilidade e do cuidado, uma contravisão do mundo laboral e da vida dos trabalhadores. O cenário ficcional de Jatobá em Crônicas está repleto de brutalidades e violências, e talvez seja por isso que o conceito de testemunho apareça ao lado da obra. E, assim, seu texto pode apresentar um novo ponto de vista para se pensar o trabalho, as relações humanas e novos pactos de responsabilidade.

Por fim, acredita-se que Jatobá, em suas obras, expõe as dramáticas dos trabalhadores e não apenas o mundo em si mesmo, evidencia o frágil e minúsculo corpo humano que trabalha 
e, por isso, como autor e testemunha, tem a necessidade de narrar e de costurar esse mundo. Jatobá não olhou nos olhos da Medusa, resgatando as metáforas que se fazem presentes nos conceitos de testemunho e de realismo, e, assim, não ficou petrificado, podendo testemunhar e fazer literatura, a qual entrega diversas chaves para análises sobre o universo laboral.

\section{Referências}

AGAMBEN, Giorgio. O que resta de Auschwitz: o arquivo e o testemunho (Homo Sacer III). São Paulo: Boitempo Editorial, 2008.

BENVENISTE, Émile. Problemas de linguística geral. São Paulo: Nacional/ EDUSP, t. 1, 1976.

O Vocabulário das Instituições Indo-europeias. v. 2: Poder, Direito, religião. Campinas: UNICAMP, 1995 b.

BENJAMIN, Walter. Experiência e pobreza. In: . Magia e técnica, arte e política: ensaios sobre literatura e história da cultura. São Paulo: Brasiliense, 1987.

BERTONI, Federico. Realismo e letteratura: una storia possibile. Torino: Einaudi editore, 2007.

BEVERLEY, John. Against Literature. Minneapolis: University of Minnesota Press, 1993. ; ZIMMERMAN, Marc. Literature and Politics in the Central America. Austin: University of Texas Press, 1990, p. 177.

CRU, Jean N. Du témoignage. Paris: Pauvert, 1967.

Témoins. Essai d'analyse et de critique des souvenirs des combattants édités en français de 1915 à 1928. Nancy: Presses universitaires de Nancy, 2006.

FLUSSER, Vilém. Contravisão. Tradução de Rui Matoso. Disponível em: <http://www.flusserstudies.net/node/319>. Acesso em: 24 fev. 2019.

FUX, Jacques. W ou o testemunho da infância. In: Letras de Hoje, Porto Alegre, v. 48, n. 4, p. 459-466, out./dez. 2013.

JATOBÁ, Roniwalter. Contos antológicos de Roniwalter Jatobá. Organização e seleção de texto de Luiz Ruffato. São Paulo: Nova Alexandria, 2009.

LAFETÁ, João Luiz. O romance atual. In: A dimensão da noite (org. Antonio Armoni Prado). São Paulo: Duas cidades/Editora 34, 2004.

LEVI, Primo. É isto um homem?. Rio de Janeiro: Rocco, 1988. Atrégua. São Paulo: Planeta de Agostini, 2004 
PEREC, Georges. W ou a memória da infância. São Paulo: Companhia das Letras, 1995.

PENNA, João Camilo. Escritos da sobrevivência. Rio de Janeiro: 7 Letras, 2013.

RICOEUR, Paul. O entrecruzamento da história e da ficção. In: Tempo e narrativa. Tomo III. Campinas: Papirus, 1997.

RUFFATO, Luiz. Roniwalter Jatobá e a literatura proletaria. In: JATOBÁ, Roniwalter.

Contos antológicos de Roniwalter Jatobá. Organização e seleção de texto de Luiz Ruffato. São Paulo: Nova Alexandria, 2009.

Literatura e trabalho: entrevista com Luiz Ruffato. In: Eixo Roda, Belo Horizonte, v. 27, n. 2, 2018.

SELIGMANN, Márcio S. O testemunho como chave ética. 2018 (48m16s). Disponível em: <https://www.youtube.com/watch?v=08RKcZ5qfx8>. Acesso em: 19 de dez. 2018.

2010.

O local do testemunho. In: Revista Tempo e Argumento. Florianópolis, v. 2, n. 1, $2010 \mathrm{~b}$.

A literatura de testemunho e a afirmação da vida. In: IHU On-Line, edição 344, set.

O local da diferença. São Paulo: Editora 34, 2005.

STERN, Mario Rigoni. Arboreto salvatico. Torino: Einaudi, 1991.

TZVETAN, Todorov. Introduction à la littérature fantastique. Ciudad de México: Premia, 1981.

Recebido em: 28/05/2019

Aceito para publicação em: 09/10/2019 